\title{
Supportive Care Needs of Patients with Cervical Cancer in the Northeast of Thailand
}

\author{
Supan UNJAI ${ }^{1}$, Busaba SOMJAIVONG ${ }^{1, *}$ and Allison BOYES ${ }^{2}$ \\ ${ }^{I}$ Adult Nursing Division, Faculty of Nursing, Khon Kaen University, Khon Kaen 40002, Thailand \\ ${ }^{2}$ School of Medicine \& Public Health, Faculty of Health, The University of Newcastle, \\ New South Wales 2308, Australia
}

('Corresponding author's e-mail: bussom@kku.ac.th)

Received: 12 February 2020, Revised: 13 July 2020, Accepted: 14 August 2020

\begin{abstract}
In this study, a descriptive design was used to explain the supportive care needs of cervical cancer patients in the Northeast of Thailand. The purposive sample was recruited from inpatient and outpatient departments of a university hospital. A total of 144 patients with cervical cancer in stage I - IV or recurrent stage completed the Thai version of the Supportive Care Needs Survey-Short Form 34 (SCNSF34 Thai version). Descriptive statistics were used to identify the domains and items of the greatest unmet need. Results showed that standardized five domain scores indicated that participant's unmet needs were highest in the health system and information domain $(\bar{x}=2.95$, S.D. $=1.15)$, and lowest in the sexuality domain $(\overline{\mathrm{x}}=1.63$, S.D. $=0.94)$. The five most frequently endorsed items of moderate to high unmet need were all from the health system and information domain as follows: receiving information about things can do to help in recovering from illness $(74.3 \%)$, receiving information from documents, charts, or paintings about illness management and side effects that may occur at home (66\%), receiving information about cancer which is under control or in remission $(63.2 \%)$, support from at least one health care staff that can discuss illness, treatment, and follow up (63.2\%), receiving written information about the essential aspects of care $(59.7 \%)$, and receiving written information about the importance of care $(59.7 \%)$. It was clear that a large proportion of cervical cancer patients in Thailand reported unmet supportive care needs. Therefore, nurses should design nursing care services that are consistent with the supportive care needs.
\end{abstract}

Keywords: Cervical cancer patients, Gynecological cancer, Supportive care, Needs, Unmet need

\section{Introduction}

Cervical cancer has been a public health problem worldwide since it is the primary cause of death among women. According to the report of the International Agency for Research on Cancer [IARC] of the World Health Organization (WHO) in 2018, there were 569,847 new cervical cancer cases worldwide, and 311,365 of these patients died. Additionally, $88 \%$ of the deaths of women from cervical cancer were found in developing countries because these women were diagnosed at the metastasis stage with delayed treatment [1]. In Thailand, cervical cancer was the 2nd most leading site of new cases of cancer in females [2]. About 10,000 new cervical cancer patients are found each year, and about 5,200 people died from cervical cancer [3].

The pathology of cervical cancer and the side effects of various treatments such as radiotherapy, chemotherapy, and surgery can cause suffering for patients. These problems are varied, from physical problems, including fatigue, chronic pain, bleeding per vaginal, urinary issues, bowel urgency, skin irritation, lymphedema to menopausal symptoms [4]. Bedsides sexual dysfunction could also be considered as one of the effects of cervical cancer. It causes a high risk of sexual intercourse and sexual 
http://wjst.wu.ac.th

satisfaction problems. Vaginal bleeding after intercourse, vaginal dryness, and vaginal stenosis odor also greatly affect sexual behavior [4-7]. It also causes psychological and emotional impacts, such as having a low coping ability, anxiety about the symptoms, diseases, treatment, uncertainty, and fear of cancer recurrence. Patients may be afraid that they cannot have sexual intercourse with their husbands anymore, which may cause their husbands to have a new wife. Such feelings may be the cause of depression and powerlessness $[5,7,8]$.

Patients need support care from close relatives and the health care team to fight everyday life challenges and lead to an effective adaptation process [9]. Supportive care helps patients and families cope with cancer and treatment: Before diagnosis, diagnostic procedures, receiving treatment, and recovering from illness or even death. Therefore, supportive care is considered important as the diagnosis and treatment because the patients will benefit from the treatment and lifestyle under the disease's effects [10]. Individual living needs include physical, information, emotional, psychological, social, spiritual, and practical, were expressed by cancer patients because they experience physical discomfort or a sense of personal crisis [11].

The literature review revealed that women with gynecologic cancer expressed unmet needs, including early diagnosis and treatment process. More aggressive cytotoxic therapy was used with gynecologic cancer patients, leading to a high risk of impairment or fertility loss. The detrimental side effects of treatment might interfere with their family planning, especially in a young woman. In addition, unmet physical, social, employment, financial, emotional, and especially psychosocial problems and spiritual needs were experienced in advanced gynecologic cancer patients [12,13]. A study on supportive care needs in patients with prostate cancer found that the patients' most supportive care needs were sexuality needs and psychological needs. Also, the recurrence of cancer led to more psychological needs and health systems, and information needs $[14,15]$. However, the studies of the supportive care need in patients with breast cancer conducted in several countries provided different results. The studies in Japan and Switzerland revealed that patients with breast cancer had the highest need for psychological needs $[16,17]$, while in China and Vietnam, patients with breast cancer had the highest need for the health system and information needs [18-20].

A growing body of literature indicates that many cancer patients have unmet supportive care needs and that the type and magnitude of the needs vary by factors such as cancer type, age at diagnosis, disease stage, gender. Very few studies have examined the unmet needs of women with gynecological cancers $[12,21]$. Thai women are not encouraged to talk about sexuality or reproductive organs due to Thai culture's belief that discussion about sex is inappropriate [22]. This may make cervical cancer patients less likely to express their problems and needs. Therefore, healthcare providers should address the lack of knowledge about the supportive care needs of these women. This study aimed to investigate the unmet supportive care needs of patients with cervical cancer.

\section{Materials and methods}

\section{Study design and population}

This was descriptive research to study the supportive care needs of patients with cervical cancer of all stages at the Radiotherapy Outpatient Department, the Gynecology Outpatient Department, and the three inpatient wards providing care services for gynecological patients receiving chemotherapy and radiation in the university hospitals in the Northeast of Thailand from August 2015 to January 2016.

A purposive sampling method was employed to select the samples. The inclusion criteria included 1) be able to communicate by listening, speaking, reading, and writing in Thai, 2) 18 years of and over, and 3) voluntarily and willing to participate in the research. The sample size was calculated from the mean of the number of new cervical cancer patients who were admitted to the university hospitals. The sample size was determined based on Krejcie \& Morgan table [23] by comparing the number of patients in the past three years was 228 people; therefore, there were 144 samples in this study. All of them were old patients who recognize that they have been diagnosed with cervical cancer. 


\section{Procedure}

This study's ethics had been approved by The Center for Ethics in Human Research committees, Khon Kaen University (HE581200). After arriving in the clinic waiting room of the outpatient department, each cervical cancer patient was invited for an interview and informed about this study in the process of collection. The eligible participant signed the consent form and completed the supportive care needs survey (Thai version). The inpatient department used the same interview process during visiting hours when the patient has no visitors and nursing interventions at $02.00-04.00$ p.m. The 1 st author collected the data in both the outpatient and the inpatient departments.

\section{Measures}

The tool used to collect data consisted of 3 parts:

1) General information: 8 items on patient's age, religion, occupation, income, education, marital status, number of children, and caregiver.

2) Medical and treatment records: 3 items assessed the medication records: Cancer staging, time of diagnosis, and treatment type.

3) The supportive care needs survey: Thai version, which was translated from Supportive care needs short survey form (SCNS-SF34) of Boyes et al. (2009) by using the back translation technique [24]. This procedure consisted of 4 steps. Firstly, forward translation, the original English version was translated to Thai by the 1 st and second authors. Secondly, review of the translated version by reviewer, two lecturers who expert in nursing discipline, and the English-speaking knowledge had reviewed the content equivalence and semantic equivalence of the Thai version compared with the original text. Then, backward translation, the Thai version was translated back to English by a bilingual person at the Khon Kaen University Language Institute. Finally, the owner of SCNS-SF34 compares the original version and the back-translated version. Cronbach's alpha coefficient of SCNSF-34 Thai version was employed to verify the reliability, and it was 0.95 , and each dimension ranged from 0.52 to 0.93 . SCNSF-34 Thai version consisted of 5 domain of supportive care needs as follows: 1) psychological needs: The needs related to emotions and problem-focused coping: 10 items; 2) health system and information needs: The needs for the information of hospital, disease, diagnosis, treatment and follow up care: 11 items; 3) patient care and support needs: The needs for coping with physical symptoms, side effects of treatment, daily living and activities: 5 items; 4) physical and daily living needs: the needs for care involving sensitivity of the health care team to respond to physical, emotional, and personal aspects and provision of alternative treatments: 5 items and 5) sexuality needs: The need for sexual relations: 3 items. Each item preceded with the stem question, "Over the past one month, what was your level of need for help...?" with the following response options "No need, irrelevant," "No need, satisfied," "Low need," "Moderate need," or "High need."

\section{Data collection \& analysis}

After the study had been approved by the Khon Kaen University Ethics Committees and permitted by the organizations mentioned above, the data were collected. The researcher strictly protected the samples who were introduced by the nurses who took care of the patients. The data were analyzed using descriptive statistics, including frequency, percentage, mean and standard deviation by the SPSS program. Standardized domain scores were calculated to enable comparison between domains. Also, the percentage of respondents who selected 'moderate' or 'high' for each item was calculated.

\section{Results and discussion}

\section{Sample characteristics}

There were 144 samples who consented to participate in this study. The samples aged $30-79$ years old, of which the average age was 52 years (S.D. =11.34). The most common age group was $50-64$ years old, accounting for $42.4 \%$. Most of the samples were Buddhists, and only one sample was Christian. The occupation of most of the samples was a farmer $(35.4 \%)$, and the monthly income was less than 5,000 Baht (50\%). Also, $71.5 \%$ of them finished primary school, and the marital status of 75.7 
http://wjst.wu.ac.th

$\%$ of the samples was married. In addition, $41.7 \%$ had three or more children. Most of the samples $(95.8$ $\%)$ had caregivers who can take care of them. The majority of caregivers were their husbands (48\%) (Table 1).

Table 1 Sample demographics characteristics compared with cervical cancer patients in the university hospitals in the Northeast of Thailand.

\begin{tabular}{|c|c|c|}
\hline \multirow[t]{2}{*}{ Characteristics } & \multicolumn{2}{|c|}{$\begin{array}{l}\text { Survey samples } \\
\quad(n=144)\end{array}$} \\
\hline & No. & $\%$ \\
\hline \multicolumn{3}{|l|}{ Age (years) } \\
\hline $18-34$ & 5 & 3.5 \\
\hline $35-49$ & 54 & 37.5 \\
\hline $50-64$ & 61 & 42.4 \\
\hline$\geq 65$ & 24 & 16.6 \\
\hline \multicolumn{3}{|l|}{ Mean age $=52.51($ S.D. $=11.34)$} \\
\hline \multicolumn{3}{|l|}{ Years range $=30-79$} \\
\hline \multicolumn{3}{|l|}{ Religion } \\
\hline Christian & 1 & 0.7 \\
\hline Buddhists & 143 & 99.3 \\
\hline \multicolumn{3}{|l|}{ Occupation } \\
\hline Self-employed & 15 & 10.4 \\
\hline Businessman & 4 & 2.8 \\
\hline Merchant & 21 & 14.6 \\
\hline Farmer & 51 & 35.4 \\
\hline Company employee & 4 & 2.8 \\
\hline Government official & 11 & 7.6 \\
\hline Other & 5 & 3.5 \\
\hline Unemployed & 33 & 22.9 \\
\hline \multicolumn{3}{|l|}{ Income (Baht) } \\
\hline$<5,000$ & 72 & 50 \\
\hline $5,000-10,000$ & 27 & 18.7 \\
\hline $10,001-15,000$ & 16 & 11.1 \\
\hline $15,001-20,000$ & 9 & 6.3 \\
\hline $20,001-25,000$ & 5 & 3.5 \\
\hline $25,001-30,000$ & 1 & 0.7 \\
\hline$\geq 30,000$ & 14 & 9.7 \\
\hline \multicolumn{3}{|l|}{ Education } \\
\hline Primary School & 103 & 71.5 \\
\hline Secondary School & 17 & 11.8 \\
\hline High Vocational Certificate & 5 & 3.5 \\
\hline Bachelor Degree & 16 & 11.1 \\
\hline Master Degree & 3 & 2.1 \\
\hline \multicolumn{3}{|l|}{ Marital status } \\
\hline Divorced/Separated & 8 & 5.6 \\
\hline Widowed & 24 & 16.7 \\
\hline
\end{tabular}




\begin{tabular}{ccc}
\hline \multicolumn{1}{c}{ Characteristics } & \multicolumn{2}{c}{$\begin{array}{c}\text { Survey samples } \\
(\mathbf{n = 1 4 4})\end{array}$} \\
\cline { 2 - 3 } & No. & \% \\
Married & 109 & 75.7 \\
Never married/single & 3 & 2.1 \\
Number of children (person) & & \\
None & 11 & 7.6 \\
1 & 20 & 13.9 \\
2 & 53 & 36.8 \\
$\geq 3$ & 60 & 41.7 \\
Have a care giver & & \\
Yes & & 95.8 \\
No & 138 & 4.2 \\
\hline
\end{tabular}

The majority of the patients had a stage III cervical cancer (29.9\%), followed by stage II (28.5\%), while there were only 7 (4.9\%) cases in stage IV. The duration of the diagnosis of the majority of the samples $(58.3$ $\%$ ) was less than 1 year and $72.2 \%$ were treated by concurrent chemo-radiotherapy treatment (Table 2).

Table 2 Sample treatment characteristics compared with cervical cancer patients in the university hospitals in the Northeast of Thailand.

\begin{tabular}{|c|c|c|}
\hline \multirow[t]{2}{*}{ Characteristics } & \multicolumn{2}{|c|}{$\begin{array}{c}\text { Survey samples } \\
(\mathrm{n}=144)\end{array}$} \\
\hline & No. & $\%$ \\
\hline \multicolumn{3}{|l|}{ Stage of cervical cancer } \\
\hline Stage I & 32 & 22.2 \\
\hline Stage II & 41 & 28.5 \\
\hline Stage III & 43 & 29.9 \\
\hline Stage IV & 7 & 4.9 \\
\hline Recurrence stage & 21 & 14.6 \\
\hline \multicolumn{3}{|l|}{ Duration of diagnosis } \\
\hline$<1$ year & 84 & 58.3 \\
\hline$\geq 1$ year & 60 & 41.7 \\
\hline \multicolumn{3}{|l|}{ Treatment received } \\
\hline Combine treatment & 104 & 72.2 \\
\hline Chemotherapy & 2 & 1.4 \\
\hline Radiotherapy & 14 & 9.7 \\
\hline Surgical & 24 & 16.7 \\
\hline
\end{tabular}

\section{Supportive care needs domains scores}

The mean score of supportive care needs in all aspects of the sample was 2.18 (S.D. $=1.08)$. Health system and information needs were the highest $(\overline{\mathrm{X}}=2.95$, S.D. $=1.15)$, followed by patient care and support needs $(\overline{\mathrm{x}}=2.43$, S.D. $=1.13)$, physical and daily living needs $(\overline{\mathrm{x}}=1.69$, S.D. $=0.97)$. Sexuality needs were the lowest $(\bar{x}=1.63$, S.D. $=0.94)$. The proportion of the participants who reported a 'moderate' or 'high' level of need for help with 34 items is shown in table 3 . It was clear that the top 5 highest supportive care needs of the samples were health system and information needs as follow: 
http://wjst.wu.ac.th

receiving information about things can do to help in recovering from illness: 107 persons (74.3\%), receiving information from documents, charts, or paintings about illness management and side effects that may occur at home: 95 persons (66\%), receiving information about cancer which is under control or in remission 91 persons $(63.2 \%)$, receiving information that there was support from at least one health care staff that can discuss illness, treatment, and follow up with: 91 persons $(63.2 \%)$, and receiving written information about the essential aspects of care 86 persons $(59.7 \%)$.

Table 3 Number and percentage of participants reporting moderate or high-level supportive care needs (n $=144)$.

\begin{tabular}{|c|c|c|c|}
\hline Rank & Item & Domain & Number (percentage) \\
\hline 1 & $\begin{array}{l}\text { Receiving information about things can do to } \\
\text { help in recovering from illness }\end{array}$ & $\begin{array}{l}\text { Health system \& } \\
\text { information }\end{array}$ & $107(74.3)$ \\
\hline 2 & $\begin{array}{l}\text { Receiving information from documents, } \\
\text { charts, or paintings about illness management } \\
\text { and side effects that may occur at home }\end{array}$ & $\begin{array}{l}\text { Health system \& } \\
\text { information }\end{array}$ & $95(66)$ \\
\hline 3 & $\begin{array}{l}\text { Receiving information about cancer which is } \\
\text { under control or in remission }\end{array}$ & $\begin{array}{l}\text { Health system \& } \\
\text { information }\end{array}$ & $91(63.2)$ \\
\hline 4 & $\begin{array}{l}\text { Support from at least one health care staff that } \\
\text { can discuss illness, treatment, and follow up }\end{array}$ & $\begin{array}{l}\text { Health system \& } \\
\text { information }\end{array}$ & $91(63.2)$ \\
\hline 5 & $\begin{array}{l}\text { Receiving written information about the } \\
\text { important aspects of care }\end{array}$ & $\begin{array}{l}\text { Health system \& } \\
\text { information }\end{array}$ & $86(59.7)$ \\
\hline 6 & $\begin{array}{l}\text { Receiving reassurance from the medical team } \\
\text { that feelings are normal }\end{array}$ & $\begin{array}{l}\text { Patient care \& } \\
\text { support }\end{array}$ & $57(39.6)$ \\
\hline 7 & Fear of metastasis & Psychological & $55(38.2)$ \\
\hline 8 & $\begin{array}{l}\text { Concern that the result of treatment is beyond } \\
\text { control }\end{array}$ & Psychological & $41(28.5)$ \\
\hline 9 & Anxiety & Psychological & $39(27.1)$ \\
\hline 10 & $\begin{array}{l}\text { More choice about which cancer specialist to } \\
\text { see }\end{array}$ & $\begin{array}{l}\text { Patient care \& } \\
\text { support }\end{array}$ & $38(26.4)$ \\
\hline 11 & Uncertainty about the future & Psychological & $33(22.9)$ \\
\hline 12 & $\begin{array}{l}\text { Receiving enough information about the } \\
\text { benefits and side effects of the treatment } \\
\text { before choosing treatment }\end{array}$ & $\begin{array}{l}\text { Health system \& } \\
\text { information }\end{array}$ & $33(22.9)$ \\
\hline 13 & Concern about relatives' and friends' anxiety & Psychological & $31(21.5)$ \\
\hline 14 & $\begin{array}{l}\text { Receiving the results of tests as soon as } \\
\text { possible }\end{array}$ & $\begin{array}{l}\text { Health system \& } \\
\text { information }\end{array}$ & $31(21.5)$ \\
\hline 15 & $\begin{array}{l}\text { Accessing counseling from a professional } \\
\text { team }\end{array}$ & $\begin{array}{l}\text { Health system \& } \\
\text { information }\end{array}$ & $31(21.5)$ \\
\hline 16 & More choice about which hospital attend & $\begin{array}{l}\text { Patient care \& } \\
\text { support }\end{array}$ & $29(13.2)$ \\
\hline 17 & Medical team being aware of emotional needs & $\begin{array}{l}\text { Patient care \& } \\
\text { support }\end{array}$ & $27(18.7)$ \\
\hline 18 & $\begin{array}{l}\text { Medical team immediately responding to } \\
\text { physical needs }\end{array}$ & $\begin{array}{l}\text { Patient care \& } \\
\text { support }\end{array}$ & $26(18)$ \\
\hline 19 & $\begin{array}{l}\text { Receiving an explanation about tests as } \\
\text { requested }\end{array}$ & $\begin{array}{l}\text { Health system \& } \\
\text { information }\end{array}$ & $23(16)$ \\
\hline
\end{tabular}




\begin{tabular}{|c|c|c|c|}
\hline Rank & Item & Domain & Number (percentage) \\
\hline 20 & $\begin{array}{l}\text { Good physical environment in the hospital or } \\
\text { clinic }\end{array}$ & $\begin{array}{l}\text { Health system \& } \\
\text { information }\end{array}$ & $23(16)$ \\
\hline 21 & Disheartenment or depression & Psychological & $19(13.2)$ \\
\hline 22 & $\begin{array}{l}\text { Receiving care as a normal patient, not as a } \\
\text { case study }\end{array}$ & $\begin{array}{l}\text { Health system \& } \\
\text { information }\end{array}$ & $19(13.2)$ \\
\hline 23 & Learning to feel in control of situation & Psychological & $18(12.5)$ \\
\hline 24 & Looking forward positively & Psychological & $18(12.5)$ \\
\hline 25 & Feelings about death and incurable conditions & Psychological & $18(12.5)$ \\
\hline 26 & Exhaustion or tiredness & $\begin{array}{l}\text { Physical \& daily } \\
\text { living }\end{array}$ & $18(12.5)$ \\
\hline 27 & Sadness & Psychological & $17(11.8)$ \\
\hline 28 & Feeling ill at all times & $\begin{array}{l}\text { Physical \& daily } \\
\text { living }\end{array}$ & $14(9.8)$ \\
\hline 29 & $\begin{array}{l}\text { Receiving information about sexual } \\
\text { relationships }\end{array}$ & Sexuality & $14(9.8)$ \\
\hline 30 & Changes in sexual feelings & Sexuality & $13(9)$ \\
\hline 31 & Painful & $\begin{array}{l}\text { Physical \& daily } \\
\text { living }\end{array}$ & $10(7)$ \\
\hline 32 & Not be able to do things that used to do & $\begin{array}{l}\text { Physical \& daily } \\
\text { living }\end{array}$ & $10(7)$ \\
\hline 33 & Changes in sexual relation & Sexuality & $10(7)$ \\
\hline 34 & Doing some housework & $\begin{array}{l}\text { Physical \& daily } \\
\text { living }\end{array}$ & $7(4.9)$ \\
\hline
\end{tabular}

The study found that the samples' highest supportive care needs were the health system and information needs domain. This may be because cervical cancer is a disease that requires ongoing followup and is affected in many ways. When the patients go back to stay at home, they will face a problem alone. There is, therefore, the desire for additional health care support and information from physicians and nurses to address such problems. Receiving enough information about ongoing care during diagnosis and treatment, stage of the disease, and side effects of treatment are what the patients needed [3,5,25]. This was consistent with the study of breast cancer patients' supportive care needs in Taiwan, Vietnam, and Iran that health systems and information needs were the highest needs of all patients $[19,20,26]$. A study found that Taiwanese women who received and underwent the curative treatment still desired the information over four months after diagnosis to deal with side effects of chemotherapy [19]. However, a number of studies provided different results, such as the supportive care needs of women with gynecologic cancer in Canada [12,21]. The highest supportive care needs in this group were psychological needs [21]. This was similar to the study of the need for supportive care needs of ovarian cancer patients in Canada that psychological needs were the highest supportive care needs among ovarian cancer patients [12].

In addition, the study of supportive care needs conducted in breast cancer patients treated in Switzerland revealed that most of the patients needed psychosocial support [16]. The study of inpatients with advanced breast cancer in Japan also indicated that psychological needs were needed by the patients [17].

From the information mentioned above, it can be concluded that patients with female genital cancers, breast cancer, and other types of cancer need supportive care the most. This may be due to the differences in the health care information that the cancer patients received. In developed countries like Canada and Japan, access to information is more convenient than in developing countries like Thailand, 
Vietnam, Iran, and China. There are some countries where the internet system is thorough, so people can easily access health information. In contrast, there are restrictions in internet access in developing countries that can make some significant better-informed decisions about their healthcare needs and improve their quality of life [27]. In addition to Thailand, the digital divide was a significant issue due to the technical structure system, culture, religion, and government policies. Therefore, accelerating the digital and innovation can deal with the digital divide [28]. In terms of the health care system, innovation is also used to provide information to patients through a computer or video. Also, patients can inquire via email or the internet, specific and suitable for specific patients [21]. As a result, there is less need for the health system and information than other needs. In addition, in a study of the supportive care needs of gynecological cancer in Canada, most of the samples' educational level was higher than the college level, found that the health system and information need was not the top 10 most frequently reported needs [21]. In contrast, in this study, most samples finished their primary school, and the highest of supportive care needs was the health system and information need. The results of the two studies are different, and that the level of education may affect the level of supportive care needs.

When each aspect was considered, it was found that the samples had the highest supportive care needs in receiving information about the things that can do to help them in recovering from the illness. This was probably because cervical cancer affected the physical aspect causing much suffering to patients due to the pathology of cervical cancer itself and side effects from various treatments. The pathology of the disease will cause abnormalities of the female reproductive organs, including pathologic vaginal discharge, bleeding after sex, vaginal bleeding, and chronic abdominal pain or chronic pelvic inflammatory disease. The patients with cervical cancer at the final stage are usually pale, have weight loss, exhaustion, fatigue, and symptoms of renal failure or uremia [3,7]. Side effects of cervical cancer treatment also affect the body and cause pain to patients. It was found that after radiation therapy, cervical cancer patients experienced gastrointestinal symptoms such as diarrhea and urinary tract symptoms, including urination frequency and having pain while urinating or cystitis. In addition, there were secretions from the vagina due to irritation from radiation therapy and fatigue, which are the chronic symptoms of cervical cancer patients [5]. Also, this study revealed that most of the samples were cervical cancer patients at the advanced stage, so the symptoms and the side effects caused pain to the patients. The majority of patients $(72.2 \%)$ were treated with multiple treatments. Therefore, the need for information about things to help recover from illness was required for self-care, face problems, and cope with the effects when the patients were discharged to home [11-13].

The sexuality needs were the least needed by the samples $(\bar{x}=1.63$, S.D. $=0.94)$, although the illness directly affected the reproductive organs, which were the vagina and cervix. This may be because patients with cervical cancer were less interested in sexual relations than before they were treated [29]. In addition, it was found that in most of the samples aged between 50 and 64 years old, sexual desire and hormone gradually decreased and that they were in menopause, causing both the physical and mental changes because of the decrease in female hormones. At the age of 60 or older, sexual desire decreases because of the decrease in sex hormones. The vagina is narrow, and the lubricant in the vagina also decreases, so when having sex, it is painful, and they are not happy with it. Sexual interest is also reduced [30]. The decrease in sexual interest may also make patients less likely to require sexual needs.

\section{Conclusions}

The findings of this study showed that the health system and information needs were mostly needed by the patients with cervical cancer. In addition, the participants had the highest supportive care needs in receiving information about things can do to help in recovering from the suffering of illness. Therefore, nurses should consider these supportive care needs and design the health services which are consistent with the supportive care needs in order to maximize the benefits of care providing to the patients with cervical cancer. 


\section{Recommendations for policy and practice}

In this study, knowledge about the supportive care needs of patients with cervical cancer was obtained. The knowledge can benefit the patients to improve nursing practice for design health services responding to the health system and information needs. For example, nurses should critically think about nursing innovation or mobile applications that can support cervical cancer patients' information to face any distress when returning to their house. In addition, nurses can use SCN-SF 34 Thai version to assess the patients' needs and provide the appropriate nursing care for each patient. In terms of policies, organizations should use this study's results to determine the appropriate care model for patients with cervical cancer.

\section{Acknowledgements}

This article is supported by the Center for Research and Training in Woman's Health and Gender (CRTGHW), Faculty of Nursing, Khon Kaen University.

\section{References}

[1] International agency for international agency for research on cancer. World source globocan 2018, Available at: https://is.gd/nOouSp, accessed September 2018.

[2] National cancer Institute. Hospital based cancer registry 2016. Eastern Printin, Bangkok, 2016.

[3] J Srisomboon. Cervical cancer. In: J Srisomboon and C Kietpeerakool (Eds.). Gynecologic cancer, The royal Thai college of obstetricians and gynecologist. Bangkok, 2011, p. 123-46.

[4] PT Ntinga and JE Maree. Living with the late effects of cervical cancer treatment: A descriptive qualitative study at an academic hospital in Gauteng. South. Afr. J. Gynaecol. Oncol. 2015; 7, 2116.

[5] KS Pfaendler, L Wenzel, MB Mechanic and KR Penner. Cervical cancer survivorship: Long-term quality of life and social support. Clin. Ther. 2015; 37, p. 39-48.

[6] H Lind, AC Waldenstro, G Dunberger, M Abany, E Alevronta, KA Johansson, C Olsson, T Nyberg, U Wildera, G Steineck and E Lundqvist1. Late symptoms in long-term gynaecological cancer survivors after radiation therapy: A population-based cohort study. Brit. J. Cancer. 2011; 105, 737-45.

[7] S Swangvaree and T Gohsiyatragoon. Quality of life in cervical cancer pre - post treatment. Thai Cancer J. 2011; 31, 137-43.

[8] American cancer society. How is cervical cancer diagnosed?, Available at: http://goo.gl/mQVSyY, accessed November 2014.

[9] BT Landmark, A Bohler, K Loberg and AK Wahl. Women with newly diagnosed breast cancer and their perceptions of needs in a health-care context. J. Clin. Nurs. 2008; 17, 192-200.

[10] D Hui, MD Cruz, M Mori, HA Parsons, JH Kwon, I Torres-Vigil, SH Kim, R Dev, R Hutchins, C Liem, D Kang and E Bruera. Concepts and definitions for "supportive care," "best supportive care," "palliative care," and "hospice care" in the published literature, dictionaries, and textbooks. Support Care Cancer 2013; 21, 659-85.

[11] MI Fitch, Supportive care framework. Can. Oncol. Nurs. J. 2008; 18, 6-24.

[12] MI Fitch and R Steele. Identifying supportive care needs of women with ovarian cancer. Can. Oncol. Nurs. J. 2010; 20, 66-74.

[13] A Akalin and G Pinar. Unmet needs of women diagnosed with gynecologic cancer: An overview of literature. J. Palliat. Care Med. 2016; 6, 3.

[14] E Ream, A Quennell, L Fincham, S Faithfull, V Khoo, J Wilson-Barnett and A Richardson. Supportive care needs of men living with prostate cancer in England: A survey. Br. J. Cancer 2008; 98, 1903-9.

[15] DP Smith, R Supramaniam, MT King, J Ward, M Berry and BK Armstrong. Age, health, and education determine supportive care needs of men younger than 70 years with prostate cancer. $J$. Clin. Oncol. 2007; 25, 2560-6. 
http://wjst.wu.ac.th

[16] S Schmid-Buchi, RJG Halfens, M Muller, T Dassen and BVD Borne. Factors associated with supportive care needs of patients under treatment for breast cancer. Eur. J. Oncol. Nurs. 2013; 17, 229.

[17] M Uchida, T Akechi, T Okuyama, R Sagawa, T Nakaguchi, C Endo, H Yamashita, T Toyama and TA Furukawa. Patients' supportive care needs and psychological distress in advanced breast cancer patients in Japan. Jpn. J. Clin. Oncol. 2011; 41, 530-6.

[18] A Au, WWT Lam, A Kwong, D Suen, J Tsang, W Yeo, J Suen, WM Ho, TK Yau, I Soong, KY Wong, WK Sze, A Ng, A Girgis and R Fielding. Validation of the Chinese version of the short-form supportive care needs survey questionnaire. Psychooncology 2011; 20, 1292-300.

[19] MN Liao, SC Chen, YC Lin, YH Hsu, HC Hung, CH Wang, MF Chen and SW Jane. Changes and predictors of unmet supportive care needs in Taiwanese women with newly diagnosed breast cancer. Oncol. Nurs. Forum. 2012; 39, E380-E389.

[20] NT Son. 2013, Supportive care needs of breast cancer patients undergoing adjuvant therapy in Hanoi, Vietnam. Master Thesis, Khon Kaen University, Thailand.

[21] R Steele and MI Fitch. Supportive care needs of women with gynecologic cancer. Cancer Nurs. 2008; 31, 284-91.

[22] A Tangmunkongvorakula, G Carmichaelb, C Banwellb, ID Utomoc and A Sleighb. Brief assessment of adult cancer patients' perceived needs: development and validation of the 34-item supportive care needs survey. J. Youth Stud. 2011; 14, 315-39.

[23] B Srisatidnarakul. The methodology in nursing research. You and I Media, Bangkok, 2011.

[24] A Boyes, A Girgis and C Lecathelinais. Brief assessment of adult cancer patients' perceived needs: Development and validation of the 34-item supportive care needs survey. J. Eval. Clin. Pract. 2009; 15, 602-6.

[25] LJ Rutten, NK Arora, AD Bakos, N Aziz and J Rowland. Information needs and sources of information among cancer patients: A systematic review of research (1980-2003). Patient Educ. Couns. 2005; 57, 250-61.

[26] A Rahmani, C Ferguson, F Jabarzadeh, A Mohammadpoorasl, N Moradi and V Pakpour. Supportive care needs of Iranian cancer patients. Indian J. Palliat. Care. 2014; 20, 224-8.

[27] M Lu. Digital divide in developing countries. J. Global Inform. Tech. Manag. 2001; 4, 1-4.

[28] W Amornsiriphong. A situation analysis of digital divide: Policy recommendation for public libraries' management. J. Mark. Manag. 2019; 6:2. 97-113.

[29] Cancer Research UK. Cervical cancer radiotherapy side effects, Available at: http://goo.gl/huCzQA, accessed November 2014.

[30] A Taylor and MA Gosney. Sexuality in older age: Essential considerations for healthcare professionals. Age Ageing 2011; 40, 538-43. 